\title{
Design and Performance Analysis of a Wine-bridge RC Harmonic Oscillation Generator with an Operational Amplifier
}

\author{
Boyan Karapenev \\ Department of the Communication Equipment and Technologies, Technical University of Gabrovo, Bulgaria
}

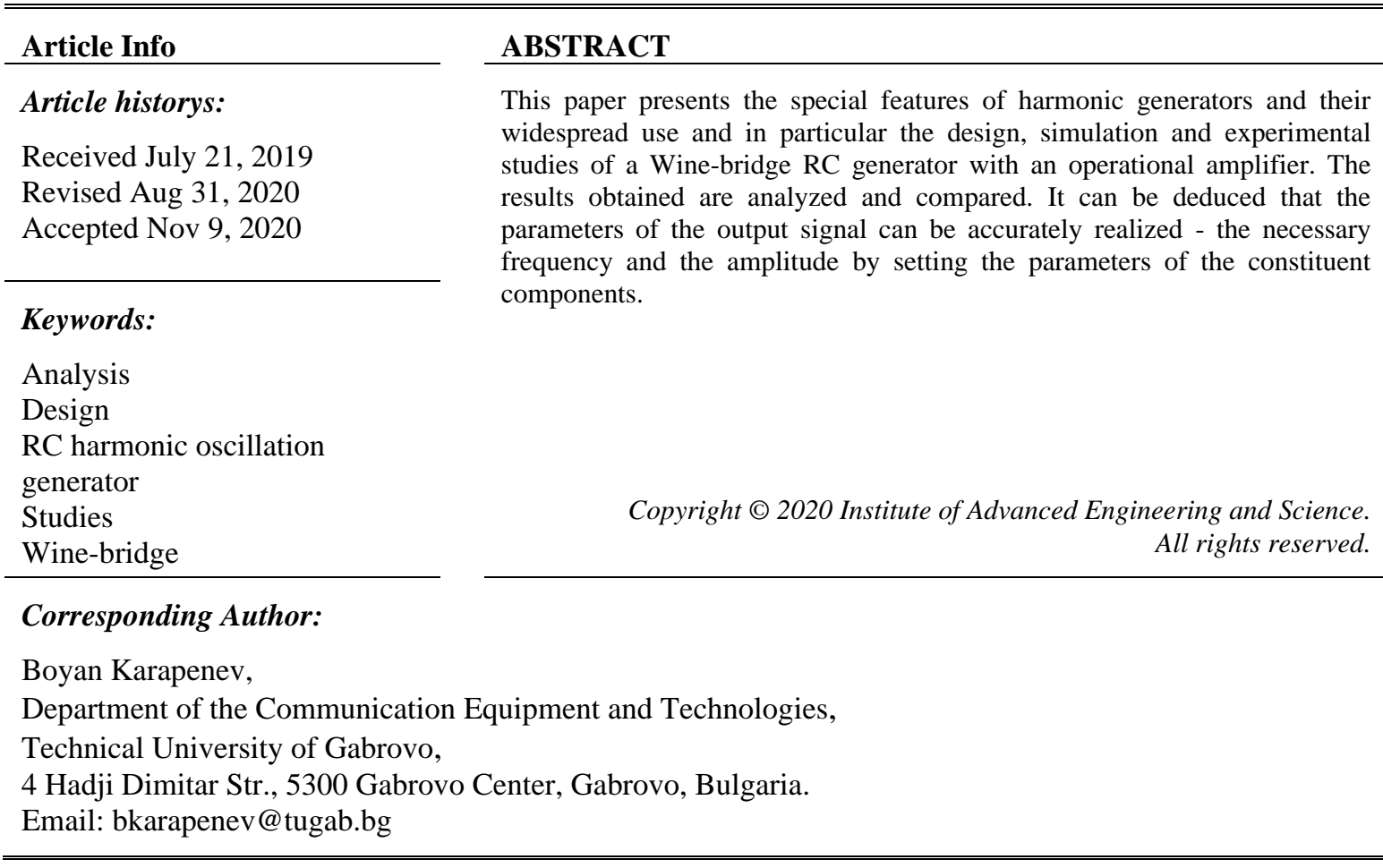

\section{INTRODUCTION}

The development of technology over the last decades has led to the need to employ electronics in an increasing proportion of human activity. This necessity induces a constant improvement of the existing and the creation of new electronic equipment, where the electronic generators find a wide application as a primary source of electrical signals.

The electronic generators are also very useful in communications [1-3]. They are the basis for creating the modern resources for radio broadcasting and radio reception based on the super heterodyne principle radio, television, telecommunications, etc. They are also used in electronic circuits associated with electromagnetic wave propagation, induction heating and many more. They are also disseminated in electronic circuits of automated instruments for control of production and other processes, in medical, measuring, musical equipment, etc.

This determines the wide variety of schemes and constructive solutions [4]. The common thing among them is that they are designed to convert DC power from the power source into non-stop electric oscillations with certain parameters.

The main topologies of the harmonic oscillation generator are based on the type of the elective circuit - LC and in particular quartz and RC generators.

The review of scientific publications in recent years, e.g. [5-20], reveals the need for in-depth research, study and analysis of the operation of the RC harmonic oscillation generators as well as their selective chains.

\section{REPRESENTATION}

The widespread use of generators leads to the need for greater accuracy and stability, and to this purpose, the schematic solutions and building elements are continually being improved. Wine-bridge RC harmonic oscillation generators are classified as those with selective frequency-determining circuit and maximum transmission coefficient, and zero-offset feedback for the generated frequency $f_{0}$. The Wine-bridge as a passive unit according to its amplitude-frequency response (AFR) is a band-pass filter. 
The block diagram of the harmonic oscillation generators is shown in Fig. 1 and it contains: DC Power Supply, Active non-linear element (bipolar, field transistor, operational amplifier or integrated circuit), selective circuit (RC set), Positive feedback loop (PFL) and load. On addition, Negative feedback loops (NFL) can be introduced to stabilize the DC mode of the active element used.

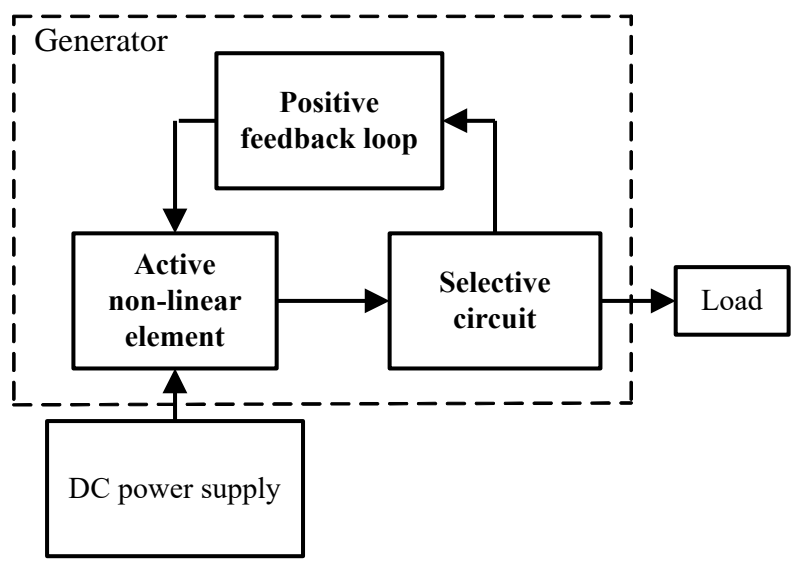

Figure 1. Block diagram of a harmonic oscillation generator

Other main qualitative parameters characterizing the harmonic oscillation generators are: relative instability of the generated frequency - $\Delta f / f_{0}$ which for RC generators takes values within the limits $10^{-2}-10^{-3}$, efficiency, non-linear distortions $(k)$ and monochromaticity of oscillation, etc.

\subsection{Design of a Wine-bridge harmonic oscillation generator with an operational amplifier}

Output data for design of the Wine-bridge harmonic oscillation generator:

- generated frequency $f_{0}=1 \mathrm{kHz}$

- output voltage $U_{0}=(0-3) \mathrm{V}$;

- load resistor $R_{\mathrm{L}}=1 \mathrm{k} \Omega$.

Operational amplifiers (OA) and transistors are the most widely used in practice in RC harmonic oscillation generators. The choice of active (amplifying) elements is based on the set output data, the gain coefficient for the operating frequency, the power dissipation and the output power in the load.

The choice of an active element is of no significance since the set operating frequency is $1 \mathrm{kHz}$ and the output voltage is in the range $(0-3) \mathrm{V}$. The OA has a very high voltage gain coefficient of $1 \mathrm{kHz}$ and their transmit frequency is $f_{\mathrm{T}} \geq 1 \mathrm{MHz}$. Low-power and medium-power transistors also possess a high static gain current $h_{21}$ and voltage coefficients. They have $f_{\mathrm{T}} \geq 100 \mathrm{MHz}$ and are used to generate high frequency signals.

The widespread and universally applied $\mu A 741$ will be chosen as the OA of the Wine-bridge RC oscillation generator. Its main catalog parameters are presented in Table 1 [21].

Table 1. A main catalog parameters of operational amplifier $\mu$ A741

\begin{tabular}{lcccccc}
\hline Operational & \multicolumn{7}{c}{ Parameters } \\
\cline { 2 - 7 } amplifier & $\mathrm{Ri}, \mathrm{M} \Omega$ & $\mathrm{Ci}, \mathrm{pF}$ & $\mathrm{Rsf}, \mathrm{M} \Omega$ & $\mathrm{A}_{0}$ & $\mathrm{R}_{0}, \mathrm{M} \Omega$ & $f_{\mathrm{T}}, \mathrm{MHz}$ \\
\hline$\mu \mathrm{A} 741$ & 2 & 1,4 & 20 & $2.10^{5}$ & 75 & 6 \\
$\mu \mathrm{A} 741 \mathrm{~A}$ & 6 & 1,4 & 60 & $5.10^{4}$ & 75 & 4 \\
\hline
\end{tabular}

In Fig. 2 is presented the circuit of the designed Wine-bridge RC oscillation oscillator with an OA with the obtained values of the elements determined in the following order:

A. determining the values of the Wine-bridge elements

It is assumed that the values of the resistors and capacitors of the PFL - Wine-bridge are equal, i.e. $R_{1}=R_{2}=R$ and $C_{1}=C_{2}=C$. The capacity of the capacitors is selected on the basis of the condition $C>500 \mathrm{pF}$ taking the value $10 \mathrm{nF}$.

The resistance of resistors $R_{1}$ and $R_{2}$ is determined by

$$
R_{1}=R_{2}=\frac{0.1}{C \cdot f_{0}}=\frac{0.1}{10.10^{-9} \cdot 1 \cdot 10^{3}}=10 \mathrm{k} \Omega
$$




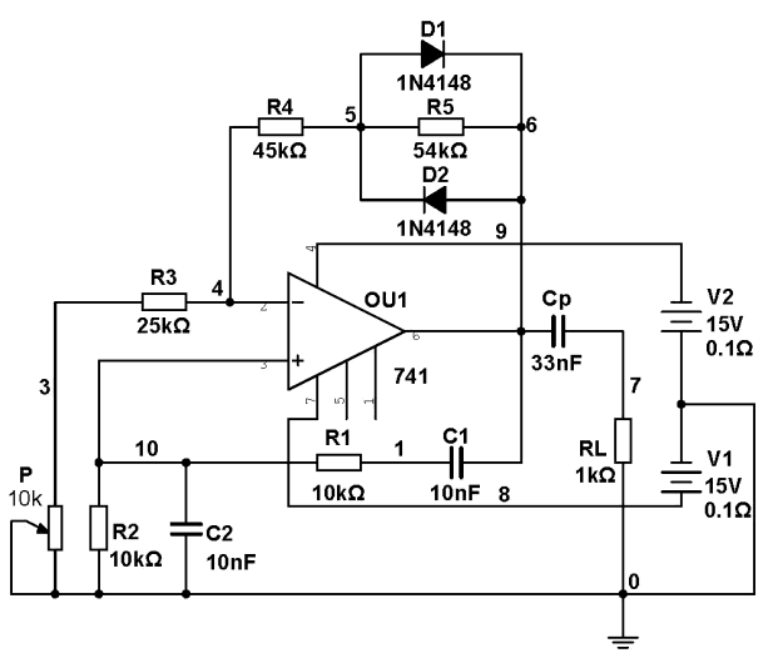

Figure 2. A circuit of Wine-bridge RC oscillation generator with an $\mathrm{OA}$

$B$. determining the average value of the resistance of the variable resistor $P$,

The determination is using the following equation:

$$
P=0.45 . R=0.45 .10 .10^{3}=4,5 \mathrm{k} \Omega
$$

and for its standard value is accepted $10 \mathrm{k} \Omega$;

C. the resistance of $R_{3}$ is determined by the ratio

$$
R_{3}=2 \cdot 5 \cdot R=2 \cdot 5 \cdot 10 \cdot 10^{3}=25 \mathrm{k} \Omega,
$$

and the resistance of resistors from NFL - by the ratios:

$$
\begin{aligned}
& R_{4}=2 . R+R_{3}=2 \cdot 10 \cdot 10^{3}+25.10^{3}=45 \mathrm{k} \Omega \\
& R_{5}=R+R_{4}=10 \cdot 10^{3}+45 \cdot 10^{3}=55 \mathrm{k} \Omega
\end{aligned}
$$

as a standard value of $R_{5}$ is chosen $54 \mathrm{k} \Omega$;

$D$. the capacity of the separator capacitor $C_{p}$ is determined by

$$
C_{p}=\frac{0.03}{f_{0} \cdot R_{L}}=\frac{0.03}{1.10^{3} \cdot 1 \cdot 10^{3}}=30 n \mathrm{~F}
$$

and for its default value is chosen $33 \mathrm{nF}$;

E. selection of the diode limiter $D_{1}-D_{2}$

The inertial time-constant of the non-linear element used must be sufficiently large for the period of the oscillations at low frequencies, such as the operating $f_{0}=1 \mathrm{kHz}$ of the designed Wine-bridge RC generator with an OA. In this case, the stabilization is done by the diode limiter - counter-related $D_{1}$ and $D_{2}$, which are also used to effectively limit the amplitude of the generated oscillations.

$1 \mathrm{~N} 4148$ is selected for diodes $D_{1}$ and $D_{2}$ according to the required differential resistance

$$
R_{i d}=\frac{U_{r}}{I_{r}}=\frac{12}{1.10^{-6}}=12 \mathrm{M} \Omega .
$$

\subsection{Simulation studies of the designed Wine-bridge $\mathrm{RC}$ oscillation generator with an $\mathrm{OA}$}

The circuit of the designed Wine-bridge RC generator with an OA in Fig. 2 was introduced into the MultiSIM working environment of Circuit Design Suite package and simulation studies have been done. The measured values of the parameters of the generated output signal with the instruments Frequency counter and Multimeter are $1.033 \mathrm{kHz}$ and $2.151 \mathrm{~V}$ respectively.

The oscillogram with the generated oscillations at the output of the RC generator is shown in Fig. 3 . It clearly shows the outgoing transition process and sets the parameters of the output signal: frequency $f_{0}=$ $1015.39 \mathrm{~Hz}$ and voltage $u_{0}=3.4 \mathrm{~V}$. The obtained results of the carried out DC operating point analysis of the Wine-bridge RC generator are presented in Table 2. From the voltage values in the indicated nodes which have dimensions $\mathrm{mV}$ and $\mu \mathrm{V}$ it is established, that the $\mathrm{OA}$ has no DC operating point mode. 


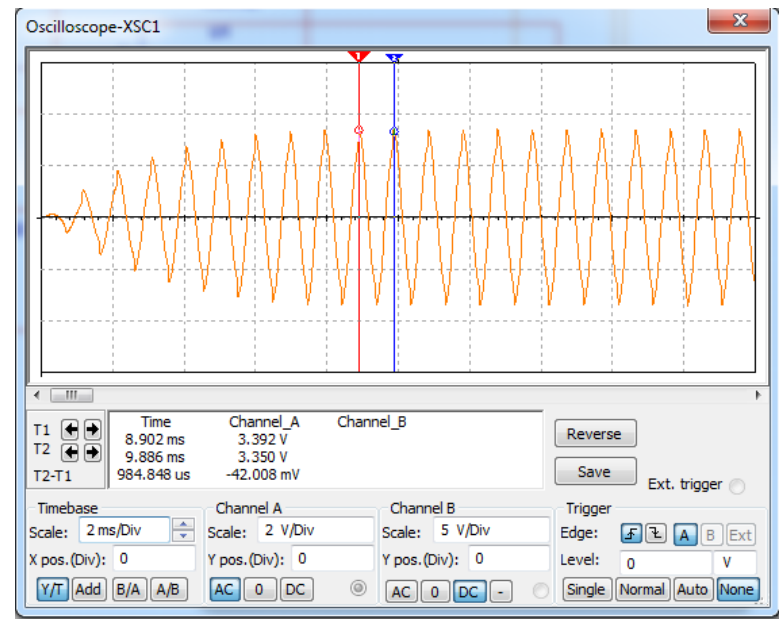

Figure 3. Oscillogram of the output signal of the designed Wine-bridge RC harmonic oscillation generator

Table 2. DC operating point of the $\mathrm{OA}$ at Wine-bridge $\mathrm{RC}$ harmonic oscillation generator

\begin{tabular}{lll}
\hline & \multicolumn{1}{c}{ Variable } & \multicolumn{1}{c}{ Operation point value } \\
\hline 1 & $\mathrm{~V}(1)$ & $-685.22188 \mathrm{u}$ \\
2 & $\mathrm{~V}(3)$ & $58.70095 \mathrm{u}$ \\
3 & $\mathrm{~V}(4)$ & $352.20573 \mathrm{u}$ \\
4 & $\mathrm{~V}(5)$ & $4.84703 \mathrm{~m}$ \\
5 & $\mathrm{~V}(6)$ & $10.18968 \mathrm{~m}$ \\
6 & $\mathrm{~V}(7)$ & 0.00000 \\
7 & $\mathrm{~V}(8)$ & $958.73002 \mathrm{~m}$ \\
8 & $\mathrm{~V}(9)$ & $-938.34793 \mathrm{~m}$ \\
9 & $\mathrm{~V}(10)$ & $-685.22189 \mathrm{u}$ \\
\hline
\end{tabular}

The amplitude-frequency (AFR) and phase-frequency (PFR) responses of the Wine-bridge as a passive unit of the structure of the RC harmonic oscillation generator are shown in Fig. 4. From the first response it is established that the bandwidth passed at the level of 0.707 ( $-3 \mathrm{~dB}$ ) varied widely - from $477 \mathrm{~Hz}$ to $5.3 \mathrm{kHz}$ and assumed a value $\Delta f=4.82 \mathrm{kHz}$. The section with a maximum and uniform transmission coefficient is broad and is set within the range from $0.8 \mathrm{kHz}$ to $2.2 \mathrm{kHz}$ which determines the value of the generated frequency $f_{0}$. From the PFR is determined the frequency with zero phase offset of the output signal versus the input whose measured value is $1.56 \mathrm{kHz}$.
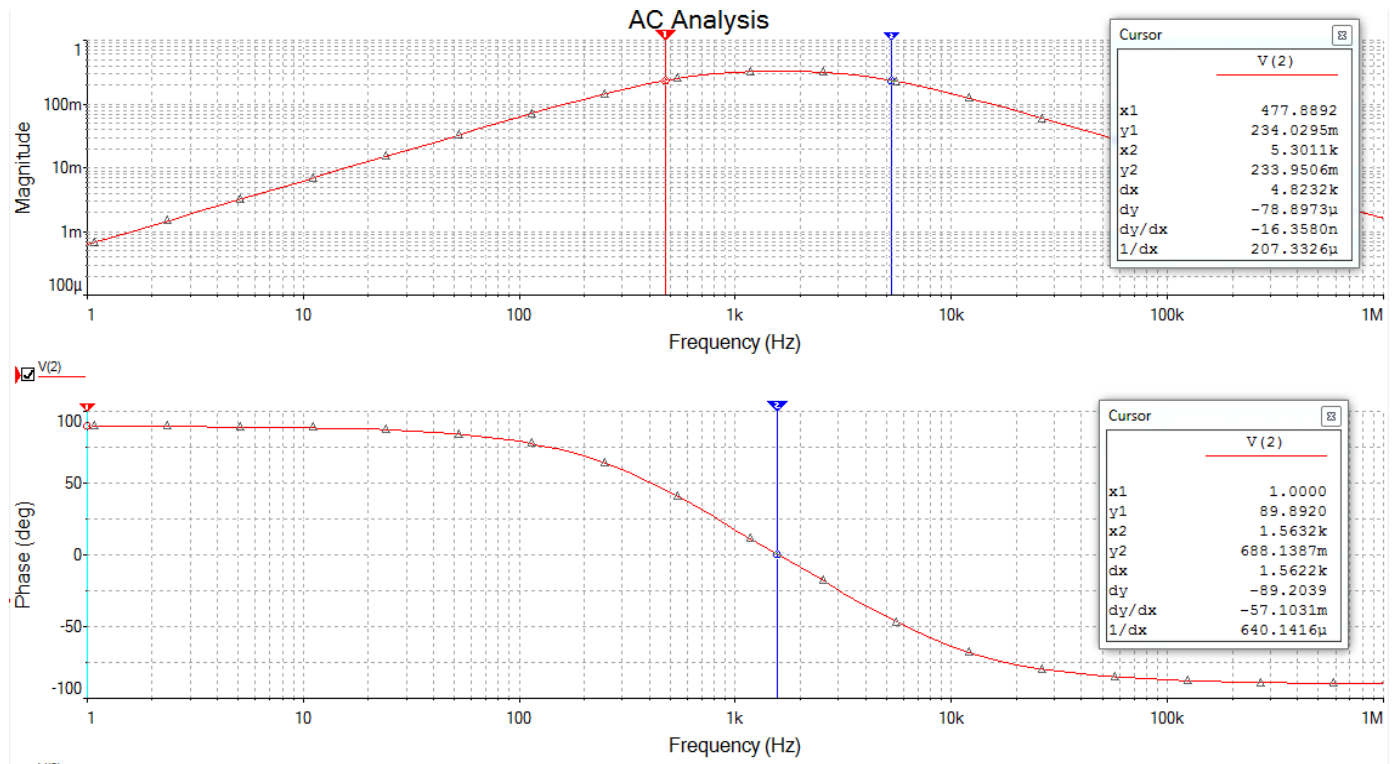

四(2)

Figure 4. AFR and PFR of the Wine-bridge as a passive unit of the structure of the RC harmonic oscillation generator 
From the simulation studies performed, the relative error between the realized and the set operating frequency can be determined with a value $\varepsilon_{f}=3.3 \%$, which in this case coincides with the relative instability parameter of the generated frequency $\Delta f / f_{0}=0.033$.

\subsection{Experimental studies of the designed Wine-bridge RC oscillation generator with an $\mathrm{OA}$}

Technical documentation of the designed Wine-bridge RC generator with an OA has been developed using the UltiBOARD module of the Circuit Design Suite package by which a laboratory model has been implemented. The assembly drawing of the developed RC generator is presented in Fig. 5 and in Fig. 6 - its 3D-image.

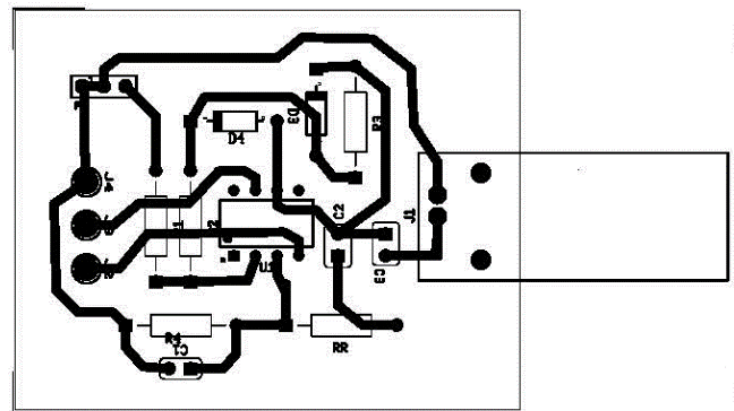

Figure 5. Assembly drawing of the developed RC generator

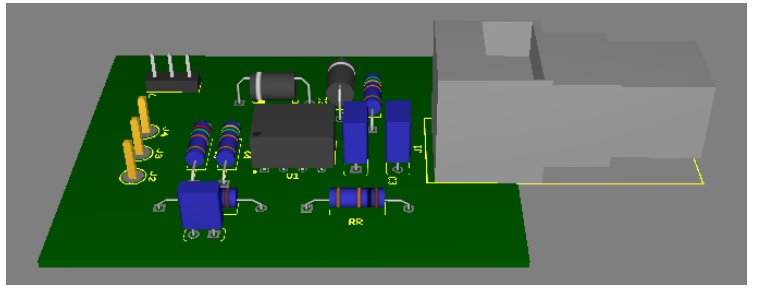

Figure 6. 3D-image of the developed laboratory model

The amplitude performances of the Wine-bridge as a passive unit for $1 \mathrm{kHz}$ and $1.1 \mathrm{kHz}$ operating frequencies are presented in Fig. 7. It is established, that they are linear with a transmission coefficient of the order of 0.3. Its minimal increase at the higher values of input voltage at the operating frequency of $1.1 \mathrm{kHz}$ is noted.

The amplitude-frequency responses (AFR) of the Wine-bridge as a passive unit for $1.14 \mathrm{~V}$ and $1.8 \mathrm{~V}$ operating voltages are presented in Fig. 8. It has been found from the AFR that the bridge performs the function of a band-pass filter with a maximum transmission coefficient of the order of 0.3 for the operating frequencies from $0.4 \mathrm{kHz}$ to $2 \mathrm{kHz}$. The pass bandwidth is expanded by increasing the input voltage, especially in the higher frequencies. The selectivity of the left slope of the AFR is greater when the input signal is larger.

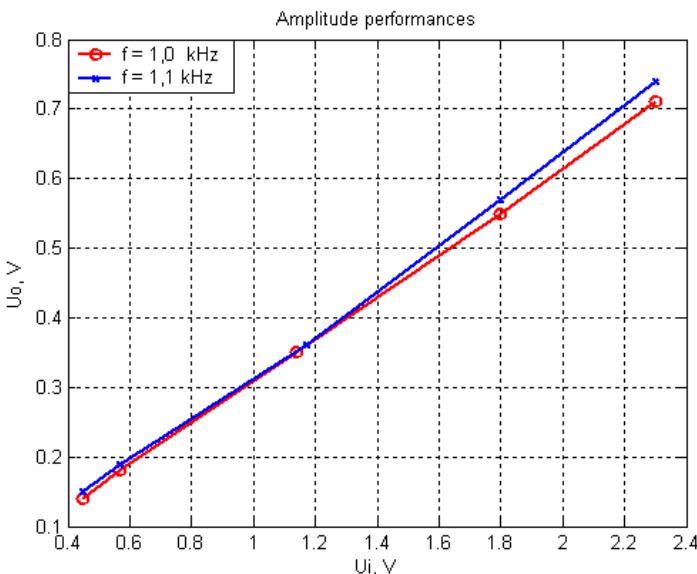

Figure 7. Transmission characteristics of the Winebridge for operating frequencies $1 \mathrm{kHz}$ and $1.1 \mathrm{kHz}$

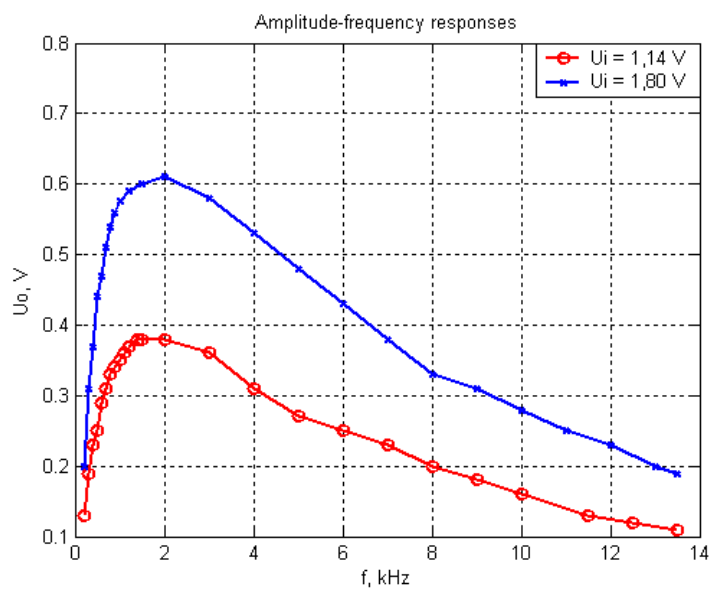

Figure 8 . AFR of the Wine-bridge 
From the AFR presented in fig. 8 the transmission coefficient and the transmitted frequency bandwidth of the Wine-bridge chain are established. For their determined values - transmission coefficient of 0.3 and the frequency range from $0.5 \mathrm{kHz}$ to $4 \mathrm{kHz}$ the conditions for balance of the amplitudes and the phase angles are fulfilled.

The obtained oscillograms of the generated signal at different values of the potentiometer $P$ are presented in Figures 9 - 11.

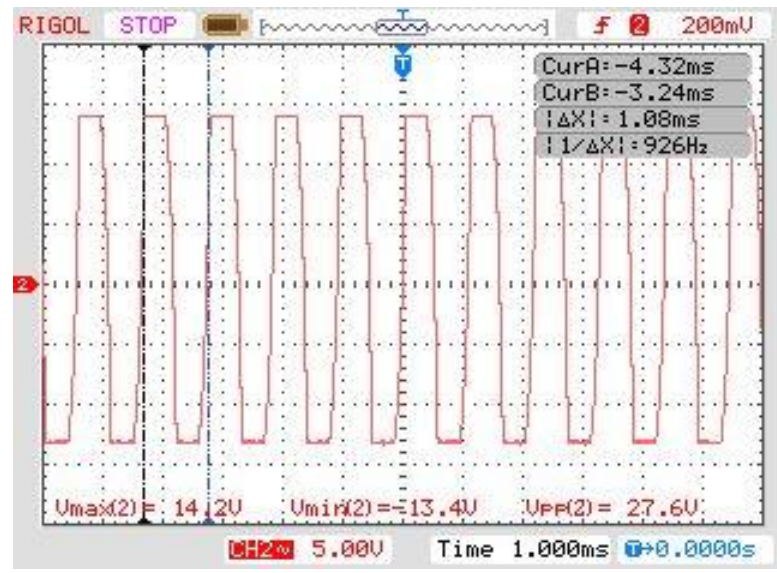

Figure 9. Oscillogram of the generated signal by a Wine-bridge $\mathrm{RC}$ generator with an $\mathrm{OA}$ at $P=8 \mathrm{k} \Omega$

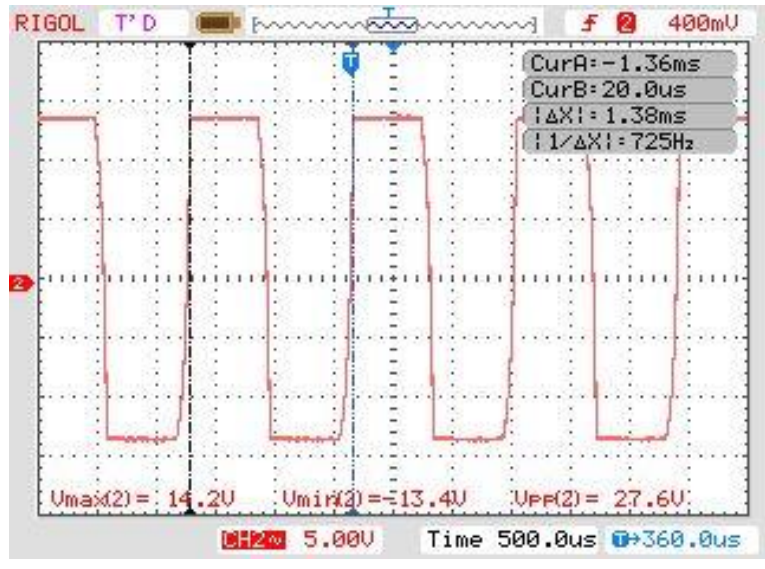

Figure 10. Oscillogram of the generated signal by a Wine-bridge $\mathrm{RC}$ generator with an $\mathrm{OA}$ at $P=4 \mathrm{k} \Omega$

From the presented oscillograms it is established that by increasing the resistance of the potentiometer $P$, connected to the inverting input, the generated frequency decreases. This dependence is represented graphically in Fig. 12. From the oscillograms it is visible that the output amplitude of the generated signal is very high and the OA is in saturation mode. The output pulses are rectangular with an amplitude of $13.7 \mathrm{~V}$, which is $1.3 \mathrm{~V}$ less than the supply voltage $+\mathrm{U}_{\mathrm{CC}}(15 \mathrm{~V})$.

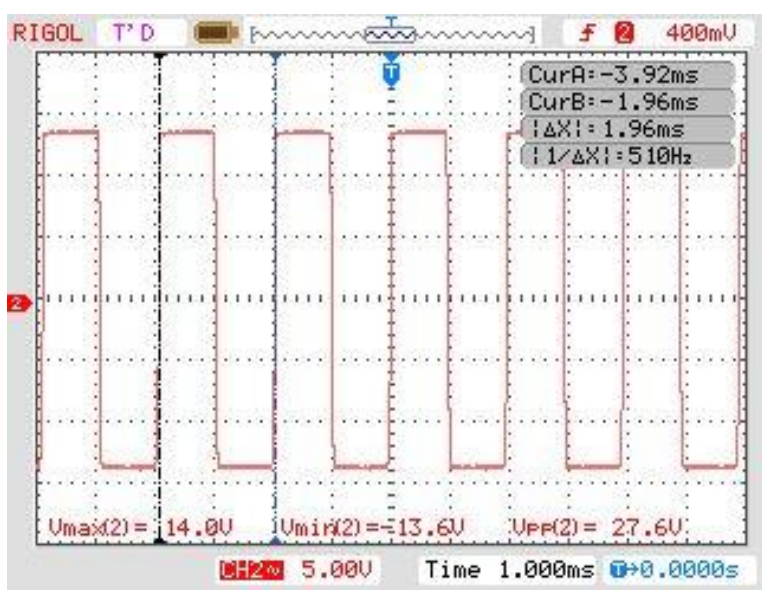

Figure 11. Oscillogram of the generated signal by a Wine-bridge RC generator with an $\mathrm{OA}$ at $P=1 \mathrm{k} \Omega$

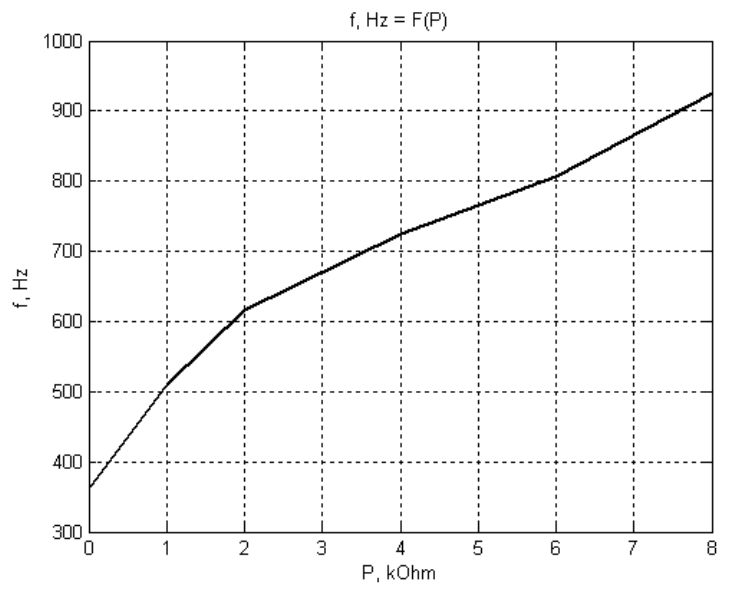

Figure 12. Generated frequency dependence of the value of potentiometer $P$

Reducing the high gain coefficient of the OA by switching on a resistor $R$ with a value of $20 \mathrm{k} \Omega$ to the non-inverting input generates a sinusoidal-wave signal with an amplitude of $1.7 \mathrm{~V}$ as shown in Fig. 13. The measured DC voltages (DC operating point) at the indicated nodes of the Wine-bridge RC generator with an $\mathrm{OA}$ are presented in Table 3.

Table 3. DC Operating Point in the Indicated Nodes of the Wine-bridge RC Oscillation Generator with an OA

\begin{tabular}{cccccccc}
\hline Node № & 1 & 3 & 4 & 5 & 6 & 7 & 10 \\
$\mathrm{U}_{=}, \mathrm{V}$ & 0.58 & 0.015 & 0.017 & 0.58 & 0.6 & 0 & 0.007 \\
\hline
\end{tabular}




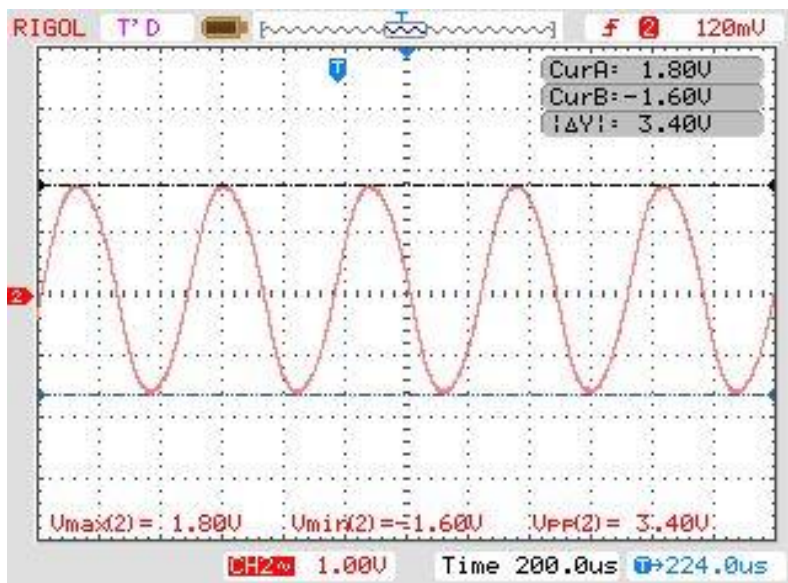

Figure 13. Oscillogram of the generated signal by a Wine-bridge $\mathrm{RC}$ generator with an $\mathrm{OA}$ when $R=20 \mathrm{k} \Omega$ is connected to the non-inverting input

The potentiometer $P$ can set the generated frequency of the output signal of the implemented harmonic oscillation generator of the nominal $f_{0}=1 \mathrm{kHz}$, and in this case the relative error will be 0 . The relative frequency error between the simulation and experimental studies at $P=9.5 \mathrm{k} \Omega$ coincides with the result obtained in the simulation results and the set value and accepts the value $\varepsilon_{f}=3.3 \%$.

From a comparison of the operation of the presented Wine-bridge $\mathrm{RC}$ generator with a circuit of a twin T-bridge RC generator [22], the high accuracy of the generated frequency coinciding with the set one is established. The relative error between the generated frequency and the nominal one at Wine-bridge RC generator can reach 0 at minimal nonlinear distortions of the generated output signal by parametric optimization by the resistance of the porentiometer $P$.

\section{CONCLUSION}

The harmonic oscillation generators are used to generate signals in the frequency range from several $\mathrm{Hz}$ to $\mathrm{MHz}$.Although the selectivity of RC generators is considerably smaller, they have some advantages: smaller sizes, suitable for integral implementation, they are not affected by dissipated magnetic fields, low cost, they are easily embedded in hybrid integrated circuits. They yield to other types of generators, however, in frequency stability. In RC generators, the reception of oscillations with small non-linear distortions is associated with the introduction of an additional non-linear negative feedback loop which also stabilizes the oscillation amplitude. The simulated and experimental results are presented for the design circuit of the Winebridge harmonic oscillation oscillator with an $\mathrm{OA}$ - main parameters of generated oscillations and oscillograms. A comparative assessment was made both between them and the set output frequency. It is established that using the variable parameter elements, such as the potentiometer in this case, the required nominal output frequency can be realized.

The Wine-bridge RC generator circuits are suitable for the construction of range low-frequency generators. By switching R-C circuits connected in parallel with adjusting the values of the RC elements, a wide range of generated frequencies can be covered, such as from a few $\mathrm{Hz}$ to $100 \mathrm{kHz}$.

The harmonic oscillation generators are used in radio transmitters to implement an amplitude or frequency modulation of low-frequency (information) signals, radio receivers and measurement techniques, to form test signals for other electronic circuits and devices, electronic-computing equipment, electronic amplifier testers, etc.

\section{REFERENCES}

[1] St. Koutsarov, 55 practical circuits of electronic filters. Sofia. Technika Publishing house, 1984.

[2] St. Koutsarov, Non-inductive electronic filters. Sofia. Technika Publishing house, 1977.

[3] St. Manolov, Ch. Tihchev. Generators. Sofia. Technika Publishing house, 1982.

[4] B. Karapenev, "A comparative assessment between the obtained parameters from the studies of RC harmonic generators”. Proceedings II, International Scientific Conference UNITECH'15, ISSN 1313-230X, 20-21 November 2015 Gabrovo, pp. II-76 $\div$ II- 80 .

[5] R. Mancini, R. Palmer, Sine-Wave Oscillator. Application Report. Texas Instruments, SLOA060 - March 2001, pp. 10-14. http://www.ti.com/lit/an/sloa060/sloa060.pdf 
[6] B. Loui, Building a JFET voltage-tuned Wien bridge oscillator, 2017. https://www.edn.com/Pdf/ViewPdf?contentItemId=4458830

[7] E. Lindberg, "The Wien Bridge Oscillator Family", In Proceedings of the ICSES-06, pp. 189-192, 2006. https://orbit.dtu.dk/files/2866059/oersted-dtu2759.pdf

[8] A. Carlosena, P. Martinez, S. Porta, "An improved Wien bridge oscillator", IEEE Transactions on Circuits and Systems, Volume 37, Issue 4, pp. 543 - 546, 1990.

[9] Y. Horie, A. Youssef, T. Miyazaki, T. Takeishi, "Ultralow-frequency design of the Wien bridge oscillator using switched capacitors", Instrumentation and Measurement IEEE Transactions on, vol. 44, no. 2, pp. 184-187, 1995.

[10] A. Carlosena, P. Martinez, S. Porta, "Wein-bridge oscillators with opamp independent oscillation frequency", Instrumentation and Measurement IEEE Transactions on, vol. 40, no. 3, pp. 644-646, 1991.

[11] T. Miyazaki, Y. Horie, A. Youssef, T. Takeishi, "Ultralow-frequency design of the Wien bridge oscillator using switched capacitors", Circuits and Systems 1994, APCCAS '94, 1994 IEEE Asia-Pacific Conference on, pp. 499-504, 1994.

[12] G. Palumbo, M. Pennisi, S. Pennisi, "Design guidelines for minimum harmonic distortion in a wien oscillator with automatic amplitude control system", Electronics Circuits and Systems 2008, ICECS 2008, 15th IEEE International Conference on, pp. 1127-1130, 2008.

[13] A. Carlosena, P. A. Martinez, S. Porta, S. Celma, "Improving single opamp oscillators", Circuits and Systems 1990. Proceedings of the $33^{\text {rd }}$ Midwest Symposium on, vol. 2, pp. 1042-1045, 1990.

[14] A. Khan, S. Bimal, K. Dey, S. Roy, "Novel RC sinusoidal oscillator using second-generation current conveyor", Instrumentation and Measurement IEEE Transactions on, vol. 54, no. 6, pp. 2402-2406, 2005.

[15] J. Casaleiro, L. Oliveira, A. Pinto, "Van der Pol Approximation Applied to Wien Oscillators", Procedia Technology, vol. 17, pp. 335, 2014.

[16] P. Martinez, A. Carlosena, S. Celma, S. Porta, "Design conditions for second order oscillators using a single operational amplifier", International Journal of Electronics, vol. 70, pp. 165, 1991.

[17] G. Komanapalli, R. Pandey, N. Pandey, "Operational Transresistance Amplifier Based Wienbridge Oscillator and Its Harmonic Analysis", Wireless Personal Communications, 2019.

[18] Raj Senani, D. R. Bhaskar, V. K. Singh, R. K. Sharma, "Sinusoidal Oscillators and Waveform Generators using Modern Electronic Circuit Building Blocks", 2016.

[19] M. Abuelma'atti, Z. Khalifa. "A memristor based Wien-bridge sinusoidal/chaotic oscillator", 2016.

[20] V. Niculescu, T. Zisu, S. Miclos, E. Vasile, "Behaviour study of a Wien-bridge chaotic oscillator", International Semiconductor Conference, $23^{\text {rd }}$ Edition, 2000.

[21] https://www.alldatasheet.com/datasheet-pdf/pdf/25555/STMICRO ELECTRONICS/UA741.html

[22] Karapenev B., Design and performance analysis of a twin T-bridge RC harmonic oscillation generator with an operational amplifier, Indonesian Journal of Electrical Engineering and Informatics (IJEEI), Vol. 7, No. 2, June 2019, pp. 338 344, ISSN: 2089-3272, DOI: 10.11591/ijeei.v7i2.694 http://section.iaesonline.com/index.php/IJEEI/article/view/694/426

\section{BIOGRAPHY OF AUTHOR}

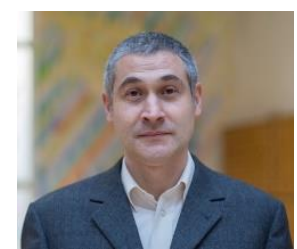

Boyan Karapenev - Department of the Communication Equipment and Technologies, Technical University of Gabrovo, Bulgaria; e-mail: bkarapenev@tugab.bg

Major Fields of Scientific Research: Communication Networks and Systems, Analog Devices / Analogue Circuits and Systems, Automation of Design and Modeling, Analog and Digital Modulations, Data Transmission and other. 